\title{
Sub-Ångstrom Atomic-Resolution Imaging from Heavy Atoms to Light Atoms
}

\author{
Michael A. O'Keefe* and Yang Shao-Horn** \\ *Materials Sciences Division, Lawrence Berkeley National Laboratory, \\ 1 Cyclotron Road, Berkeley, CA 94720, U.S.A. \\ **Department of Mechanical Engineering, Massachusetts Institute of Technology, \\ 77 Massachusetts Avenue, Cambridge, MA 02139, U.S.A.
}

\section{Dedicated to Professor John M. Cowley on the occasion of his 80th birthday.}

Corresponding Author:

email

phone

fax:

mailing address:

Running head:

Alternative running head:

\author{
Michael A. O'Keefe, \\ maok@1bl.gov \\ 510-486-4610 \\ 510-486-5530
}

\section{DISCLAIMER}

This document was prepared as an account of work sponsored by the United States Government. While this document is believed to contain correct information, neither the United States Government nor any agency thereof, nor The Regents of the University of California, nor any of their employees, makes any warranty, express or implied, or assumes any legal responsibility for the accuracy, completeness, or usefulness of any information, apparatus, product, or process disclosed, or represents that its use would not infringe privately owned rights. Reference herein to any specific commercial product, process, or service by its trade name, trademark, manufacturer, or otherwise, does not necessarily constitute or imply its endorsement, recommendation, or favoring by the United States Government or any agency thereof, or The Regents of the University of California. The views and opinions of authors expressed herein do not necessarily state or reflect those of the United States Government or any agency thereof, or The Regents of the University of California.

Ernest Orlando Lawrence Berkeley National Laboratory is an equal opportunity employer.

Lawrence Berkeley National Laboratory -- LBNL-52090 


\title{
Sub-Ångstrom Atomic-Resolution Imaging from Heavy Atoms to Light Atoms
}

\author{
Michael A. O'Keefe* and Yang Shao-Horn** \\ *Materials Sciences Division, Lawrence Berkeley National Laboratory, 1 Cyclotron Road, \\ Berkeley, CA 94720 \\ **Department of Mechanical Engineering, Massachusetts Institute of Technology, \\ 77 Massachusetts Avenue, Cambridge, MA 02139
}

\section{ABSTRACT}

John Cowley and his group at ASU pioneered the use of transmission electron microscopy (TEM) for high-resolution imaging. Three decades ago they achieved images showing the crystal unit cell content at better than $4 \AA$ resolution. Over the years, this achievement has inspired improvements in resolution that have enabled researchers to pinpoint the positions of heavy atom columns within the cell. More recently, this ability has been extended to light atoms as resolution has improved. Sub-Ångstrom resolution has enabled researchers to image the columns of light atoms (carbon, oxygen and nitrogen) that are present in many complex structures. By using sub-Ångstrom focal-series reconstruction of the specimen exit surface wave to image columns of cobalt, oxygen, and lithium atoms in a transition metal oxide structure commonly used as positive electrodes in lithium rechargeable batteries, we show that the range of detectable light atoms extends to lithium. HRTEM at sub-Ångstrom resolution will provide the essential role of experimental verification for the emergent nanotech revolution. Our results foreshadow those to be expected from next-generation TEMs with $\mathrm{C}_{\mathrm{S}}$-corrected lenses and monochromated electron beams.

KEYWORDS: sub-Ångstrom, atomic-resolution, HREM, lithium battery, FSR, ESW 


\section{INTRODUCTION}

Resolution was first defined in terms of the classic case of separation of adjacent objects (Rayleigh, 1874). Considerations of noise and coherence in detected images require modification of this simple definition (for a thorough discussion see den Dekker \& van den Bos, 1997). Nevertheless, resolution requires the ability to produce images showing distinct separation of discrete objects (in the case of high-resolution TEM, discrete peaks corresponding to atoms, or to columns of atoms seen end-on). Note that demonstration of a resolution of $|\mathbf{d}|$ requires the presence of the corresponding spatial frequency $1 /|\mathbf{d}|$ in the image diffractogram (either the intensity spectrum or the power spectrum). However, the mere presence of the $1 /|\mathbf{d}|$ frequency is not sufficient to establish a corresponding resolution of $|\mathbf{d}|$ (O'Keefe, 1979).

Resolution can be thought of in terms of the number of significant (non-empty) sampling points in the image - the finer the real-space sampling of the electron wave (at the specimen exit surface) that the microscope can achieve, the higher is its resolution. Higher resolution not only allows the separation of closer objects, the finer sampling improves the detection of weaker signals, thus making possible the imaging of lighter atoms in the presence of heavier ones.

Improvements in resolution can result in more accurate measurement of physical properties. In turn, the improved measurements made possible by higher resolution can lead to new understandings of the reasons for these properties. Over the past three decades, improvements in transmission electron microscope (TEM) resolution have enabled materials scientists to move from general observations of large-scale defects (grain boundaries, dislocations) to studies of details within the crystal unit cell. Recent advances have allowed the imaging of all the atoms within the unit cell, as well as the study of non-periodic defects at the atomic level. 


\section{BACKGROUND}

Early studies at $7 \AA$ resolution revealed the positions of crystallographic shear planes within unit cells of transition metal oxides (Allpress, 1969). Positions of metal-oxide octahedra appeared at $3.5 \AA$ resolution (Iijima, 1971). Individual metal-atom columns became accessible in alloys at

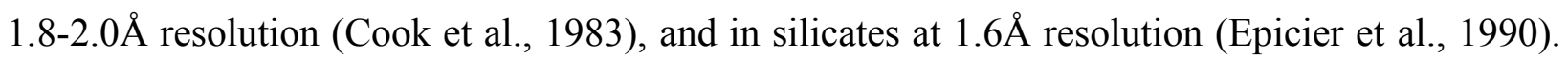
Software for simulation of HREM images from structural models was able to explain the images and confirm interpretations of them, (Allpress et al., 1972; Lynch \& O'Keefe, 1972; Anstis et al., 1973; O'Keefe, 1973; Lynch at al, 1975; O'Keefe \& Sanders, 1975: O'Keefe et al., 1978).

Resolution limits, set by phase changes imposed by spherical aberration (Scherzer, 1949), remain close to $1.5 \AA$ for uncorrected mid-voltage TEMs and $1 \AA$ for high-voltage ( $\geq 1 \mathrm{MV})$ TEMs. Methods to overcome the "Scherzer limit" by correcting for phase changes include focal-series reconstruction of the electron wave at the specimen exit surface (Schiske, 1973; Van Dyck \& Op de Beeck 1990), holography (Lichte, 1991), and hardware correction of $\mathrm{C}_{\mathrm{S}}$ (Haider et al., 1995).

A simple linear reconstruction, from five images obtained over a range of focus values, improved the resolution of an image of staurolite obtained on a JEOL ARM-1000 from $1.6 \AA$ to $1.38 \AA$ and allowed the imaging of oxygen atoms (Wenk et al., 1992). Following on from this result, the One-Ångstrom Microscope (OÅM) project (O'Keefe, 1993; O’Keefe et al., 2001b) was created to attain sub-Ångstrom resolution using software for focal-series reconstruction (Coene et al., 1996; Thust et al., 1996). The OÅM has been shown to be capable of successfully generating the specimen exit-surface wave (ESW) to $0.89 \AA$ resolution in diamond (Wang et al., 1999), and $0.78 \AA$ in silicon (O'Keefe et al., 2001a). 


\section{THEORY}

\section{Resolution}

Changes imposed on the specimen exit-surface wave $\Psi_{\mathrm{E}}(\mathbf{u})$ by the objective lens can be described as $\exp \{-\mathrm{i} \chi(\mathbf{u})\}$ where $\chi(\mathbf{u})$ is the objective lens phase function and $\mathrm{u}$ is spatial frequency. The phase change due to objective lens defocus $\varepsilon$ and spherical aberration coefficient $\mathrm{C}_{\mathrm{S}}$ at an electron wavelength $\lambda$ is

$$
\chi(\mathbf{u})=\pi \varepsilon \lambda|\mathbf{u}|^{2}+\pi \mathrm{C}_{\mathrm{S}} \lambda^{3}|\mathbf{u}|^{4} / 2
$$

At optimum defocus (extended Scherzer defocus), $\varepsilon_{X}=-\sqrt{ }\left(3 C_{S} \lambda / 2\right)$, phase changes due to spherical aberration can be offset by defocus to produce same-sign linear transfer (the "passband") of diffracted information into the image out to a spatial frequency $|\mathbf{u}|_{X}$, equivalent to a resolution of

$$
\mathrm{d}_{\mathrm{X}}=0.64 \mathrm{C}_{\mathrm{S}}{ }^{1 / 4} \lambda^{3 / 4}
$$

A plot of $\sin \chi(\mathbf{u})$, the microscope contrast transfer function (CTF), shows the phase-governed linear transfer of diffracted information into the image as a function of spatial frequency, $|\mathbf{u}|$.

\section{Information Limit}

The incident electron beam has partial spatial and temporal coherence. Like the Scherzer phase limit, these factors impose limits on how high a spatial frequency can be transferred from the exit-surface wave to the image. Partial temporal coherence manifests as spread of focus, and partial spatial coherence as incident beam convergence (O'Keefe and Sanders, 1975). These effects restrict transfer and attenuate the microscope CTF with 'damping envelope' functions (Frank 1973, Wade and Frank 1977). 
The CTF damping envelope function for temporal incoherence has the form

$$
\mathrm{E}_{\Delta}(\mathbf{u})=\exp \left\{-1 / 2 \pi^{2} \lambda^{2} \Delta^{2}|\mathbf{u}|^{4}\right\}
$$

where $\Delta$ is the standard deviation of a Gaussian spread-of-focus. The damping envelope reduces transfer to a level of $\exp (-2)$ or $13.5 \%$ at the cutoff frequency $|\mathbf{u}|_{\Delta}=(\pi \lambda \Delta / 2)^{-1 / 2}$, leading to an absolute information limit for the microscope of

$$
\mathrm{d}_{\Delta}=1 /|\mathbf{u}|_{\Delta}=\sqrt{ }(\pi \lambda \Delta / 2)
$$

The $\Delta$ parameter includes effects that change microscope focus over the image acquisition time, such as lens current ripple and high-voltage noise and ripple, as well as incident beam energy spread due to intrinsic gun spread and the Boersch contribution (O'Keefe et al., 2002). Then

$$
\Delta=\mathrm{C}_{\mathrm{C}} \sqrt{ }\left\{4 \sigma^{2}(\mathrm{I}) / \mathrm{I}^{2}+\sigma^{2}(\mathrm{E}) / \mathrm{E}^{2}\right\}
$$

where $C_{C}$ is the chromatic aberration coefficient for the objective lens, $\sigma(\mathrm{I}) / \mathrm{I}$ is the fractional rms ripple in lens current, and $\sigma(\mathrm{E}) / \mathrm{E}$ is the rms energy spread in the electron beam (including highvoltage noise and ripple) as a fraction of the total beam energy.

\section{Spatial Coherence}

The damping envelope function for a Gaussian-weighted incident beam convergence is

$$
\mathrm{E}_{\alpha}(\mathbf{u})=\exp \left\{-\pi^{2} \alpha^{2}\left(\varepsilon+\lambda^{2} \mathrm{CS}_{\mathrm{S}}\right)^{2} \mathbf{u}^{2}\right\}
$$

where $\alpha$ is the standard deviation of a Gaussian over the range of angles in the convergent cone; $\alpha$ is 0.77 times the measured semi-angle (Malm and O'Keefe, 1993).

Convergence and spread of focus impose limits on lens transfer at higher spatial frequencies. The convergence limit varies with defocus and does not impose an absolute limit to microscope information transfer, unlike the spread of focus. 


\section{METHODS}

\section{Initial Observations}

Early HRTEM images of metal oxides, such as $\mathrm{Ti}_{2} \mathrm{Nb}_{10} \mathrm{O}_{29}$, taken at Scherzer defocus (Iijima, 1971), showed projections of the structure at spacings down to the $3.8 \AA$ tunnels between metaloxygen octahedra (Fig. 1a). Images of the same areas obtained at larger values of underfocus contained confusing mixtures of spacings, but sometimes showed finer details of the structure than images at Scherzer defocus (Fig. 1b). In the case of $\mathrm{Ti}_{2} \mathrm{Nb}_{10} \mathrm{O}_{29}$, the image at twice the Scherzer underfocus is no longer a projection showing the $3.8 \AA$ tunnels within blocks of metaloxygen octahedra, but simulations confirmed that it shows the $2.8 \AA$ tunnels between overlapping blocks (Fig. 1b), with the $3.8 \AA$ tunnels missing (Anstis \& O'Keefe, 1976).

Because the mid and high frequencies (large and small tunnels) are spatially separated, $\mathrm{Ti}_{2} \mathrm{Nb}_{10} \mathrm{O}_{29}$ is a good example to illustrate how transfer changes with defocus. However, in many structures these different spacings overlap. In such structures, defocus to non-Scherzer values will appear to produce shifted or missing "atoms" (i.e., spots that can be misinterpreted as atom positions), or even to add spurious "atoms" to the image.

Because increased underfocus provides smaller details, it is possible to test model structures by comparing an experimental focal series with a simulated focal series (e.g., Epicier et al., 1990). However, the fit of experiment and simulation is distributed over several images and it is difficult to get an idea of the "goodness" of the match. A more-convenient way to compare a model and experimental images would obviously be to combine information from several images - in effect, using the post-resolution information to extend the microscope resolution to its information limit - to produce one image containing properly-phased spacings at both mid and 
high frequencies. In the course of a 3-D reconstruction experiment (Downing et al., 1990), the resolution of a JEOL ARM-1000 was improved from a normal $1.6 \AA$ to $1.38 \AA$ by combining information from focal series of five images of a staurolite specimen (Wenk et al., 1992). The result was confirmed by image simulation (Fig. 2).

One consequence of improved resolution is the ability to image lighter atoms. Focal series reconstruction from five staurolite images clearly shows oxygen atoms at $1.38 \AA$ resolution in the reconstructed image (Fig. 2c), particularly the oxygen-metal-oxygen string positioned vertically in the center of the unit cell (Wenk et al., 1992). Oxygen atoms also appear at similar resolutions

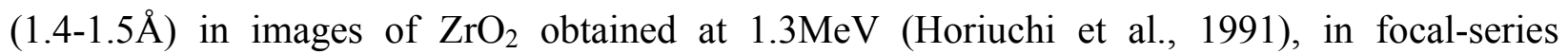
reconstructions of $\mathrm{BaTiO}_{3}$ (Jia \& Thust, 1999), and in $\mathrm{C}_{\mathrm{S}}$-corrected images of perovskites (Jia et al., 2003). Reconstruction at sub-Ångstrom resolution has produced images showing even lighter atoms, including carbon (O'Keefe at al, 2001b) and nitrogen (Kisielowski et al., 2001).

\section{Sub-Ångstrom Microscopy}

For the best-possible resolution, a microscope should have a very good information limit and a means to extend its resolution to that limit. Information limit is a function of the microscope's spread of focus (Eqn. 4) and is strongly dependent on the total energy spread in the incident electron beam (Eqn. 5). To keep energy spread low, we require a microscope with a fieldemission electron source. Such a microscope can be used to produce sub-Ångstrom resolution by phase correction (either with holography or by focal-series reconstruction). The OneÅngstrom Microscope (OÅM-CM300FEG/UT) is a combination of reconstruction software with a highly stable field-emission TEM (O'Keefe, 1993). 
The hardware part of the OAM is an improved CM300FEG/UT. Ordinarily, the CM300FEG/UT has lens current and high-voltage power supplies that are stable to one part per million for a spread of focus of $36 \AA$ and an information limit of 1.07Å (Bakker et al., 1996). The OÅMCM300FEG/UT uses improved power supplies with better stabilities to achieve beam energy spread of $0.85 \mathrm{eV}$ FWHH (O'Keefe et al., 2002), spread of focus of $20 \AA$, and information limit of $0.78 \AA$ (O'Keefe et al., 2001b). CTFs reveal that, although the Scherzer resolution (the upper limit of the main passband) remains the same for the two microscopes, the smaller spread of focus of the OAM-CM300FEG/UT extends the information limit from the $1.07 \AA$ of the standard CM300 (Fig. 3a) to $0.78 \AA$ (Fig. 3b).

The software part of the OÅM uses focal-series reconstruction code (Coene et al., 1996; Thust et al., 1996) to compute an estimate of the sample exit-surface electron wave (ESW) from a focal series of ten to twenty images. Resolution in the computed ESW is limited only by the highest spatial frequency contained in the images of the focal series. Under proper conditions, the series can contain information to the information limit of the microscope (O'Keefe, 2001). The final result is the phase of the ESW, since the phase should be proportional to a projection of the specimen structure (Cowley \& Iijima, 1972).

\section{Spatial Coherence}

Although it does not contribute to the information limit, spatial coherence can limit transfer into any given image. At Scherzer defocus, the OÅM's temporal-coherence-limited CTF (Fig. 3b) is severely damped at higher frequencies when the incident beam convergence of $\alpha=0.25$ milliradian is applied (Fig. 3c). Increasing the microscope underfocus improves transfer at higher spatial frequencies, only slightly for the second-passband $(\mathrm{n}=2)$ condition (Fig. $3 \mathrm{~d})$, but more 
for higher-passband conditions (Fig. 3e). For $n=36$, the main transfer extends from $0.93 \AA$ to $0.85 \AA$. However, at high underfocus there is reduced transfer of midrange frequencies.

The effects of defocus exhibited by images of $\mathrm{Ti}_{2} \mathrm{Nb}_{10} \mathrm{O}_{29}$ (Fig. 1), may be illustrated by the CTFs of figure 3 (even though these are computed for different resolution). The main passband moves to higher frequencies in going from the $\mathrm{n}=0$ condition (Fig. $3 \mathrm{c}$ ) to the $\mathrm{n}=2$ condition (Fig. 3d). For the JEOL 100B the defocus change moved the main passband from a spatial frequency that imaged the large tunnels (Fig. 1a) to a higher spatial frequency able to image the small tunnels (Fig. 1b). Of course, the same defocus change also misphased the spatial frequency of the large tunnels by introducing a positive-going mid-range peak (Fig. 3d), resulting in scrambled contrast at the large tunnel positions.

Another way to examine effects of spatial coherence on transfer into the image is to plot a focusvariation transfer function (FVTF). Just as a CTF shows transfer at one defocus over a range of spatial frequencies, a FVTF shows transfer at one frequency over a range of defocus (O'Keefe at al, 2001a,b). The FVTF separates the effects of spherical aberration from convergence, and shows how transfer of any particular spatial frequency $u_{\mathrm{hkl}}$ is confined to a Gaussian packet with a defocus range centered on the alpha-null defocus of $\varepsilon_{\alpha}^{0}\left(u_{\mathrm{hkl}}\right)=-\mathrm{C}_{\mathrm{S}}\left(\lambda \mathrm{u}_{\mathrm{hkl}}\right)^{2}$. The packet width is independent of $\mathrm{C}_{\mathrm{S}}$ and is a function of the convergence semiangle $\alpha$. At a cutoff value where packet transfer drops to $\exp (-2)$, the packet width is $\pm \varepsilon_{\alpha}^{2 \sigma}\left(\mathrm{u}_{\mathrm{hkl}}\right)= \pm \sqrt{ } 2 /\left\{\pi \alpha \mathrm{u}_{\mathrm{hk}}\right\}$.

To image carbon atoms at the correct positions in a [110] "dumbbell" image from a test specimen of diamond, the final image must include contributions from all four sets of diffracted beams out to the 004 spacing of $0.89 \AA$. The FVTF for [110] diamond (Fig. 4) shows how transfer at the four diffracted-beam frequencies is confined to four defocus packets centered on 
the alpha-null defocus of each spatial frequency. Within the packets, the diffracted beam phases (and thus the transfer strengths) oscillate at periods that are integer sub-multiples of the Fourier image period for the projected unit cell. For a unit cell parameter of $\mathbf{d}$, the diffracted beams reach identical relative phases (and produce identical images) at defocus periods of $2|\mathbf{d}|^{2} / \lambda$. Proposed for light optics by Cowley \& Moodie (1957a), the Fourier image effect was first demonstrated for electrons by Iijima and O'Keefe (1979). Subsequently, it has been shown that the Fourier image defocus range is confined to the region of overlap of the FVTF packets for extended-resolution conditions (O'Keefe et al., 2001b).

For a convergence semiangle as large as 0.25 milliradian, the packets are still sufficiently broad to allow substantial overlap in defocus. In the case of diamond, the overlap under OÅM conditions extends from the lower limit of the 004 packet to the upper limit of the 113 (and 022) packets (Fig. 4). Within this overlap range, it is possible to obtain a full range of Fourier images with contributions from all the beams and a resolution corresponding to the 004 spacing $(0.89 \AA)$. To form a reliable high-resolution image requires that transfer from all the diffracted beams be approximately equal. Since each packet is attenuated by spread of focus damping (the 004 packet has a maximum excursion only $28 \%$ of that of the 111 packet), optimum defocus is close to that at which all the packets have about the same height, at approximately $-3000 \AA$ (Fig. 4).

\section{Three-fold Astigmatism}

One requirement for sub-Ångstrom imaging is correction of the objective lens three-fold astigmatism. Prior to correction, a test specimen of [110] diamond, imaged under overlap conditions (Fig. 4), produced a non-intuitive image. The image failed to show the expected "dumbbell" character (Fig. 5a), although a Fourier transform showed the [110] pattern with a 
very weak 004 spot (Fig. 5b). Averaging of the experimental image produced a three-fold pattern (Fig. 5c) that could be matched by a simulated image (Fig. 5d) only when a three-fold astigmatism value of $2.25 \mu \mathrm{m}$ was included (O'Keefe, 1998). Interestingly, changing the phases of the spots making up the image intensity spectrum by imposition of the known diamond symmetry, first as a vertical mirror (Fig. 5e), then as a horizontal one (Fig. 5f), produced an image that was close to the expected symmetry. A line trace in the 004 direction confirmed that

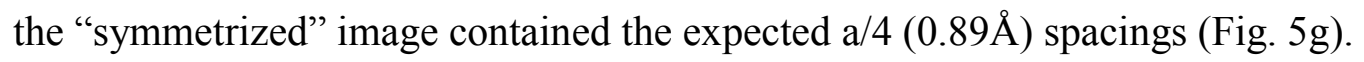

Although symmetrization can be used for illustration, it has no ability to produce the correct absolute phase (image peaks will not necessarily correspond to atom positions), and it cannot be used even for illustration unless specimen symmetry is known. To allow the OÅM to produce real sub-Ångstrom images, we corrected three-fold astigmatism with a hardware method proposed by Typke, using existing two-fold stigmator coils to produce an approximate three-fold field (Typke \& Dierksen, 1995). The method reduced the OAM three-fold astigmatism from $2.25 \mu \mathrm{m}$ to $0.03 \mu \mathrm{m}$, negligible at the OÅM information limit (O'Keefe et al., 2001b).

After correction of the three-fold astigmatism, a "single-shot" image of [110] diamond obtained in the overlap range shows the expected symmetry (Fig. 5h); the C-C "dumbbells" can be clearly observed at a spacing of $0.89 \AA$ (Wang et al., 1999). The diffractogram (Fig. 4i) from the threefold-corrected image has a much stronger 004 peak than the diffractogram of the uncorrected image, corresponding to better transfer of the $0.89 \AA$ information (since the contributing $004 \bullet 000$ and $000 \bullet 00 \overline{4}$ diffracted beam interferences are no longer oppositely phased by three-fold astigmatism). 


\section{Focal-Series Reconstruction}

As a final test of the OÅM's ability to image diamond we used a focal series of twenty diamond images reconstructed to the exit-surface wave using the Philips/Brite-Euram software for focalseries reconstruction by Coene and Thust (Coene et al., 1996; Thust et al., 1996). The phase of the ESW showed the expected dumbbells (Fig. 4j) more clearly than the "single-shot" image (O’Keefe et al., 2001b).

\section{RESUlts}

Following the successful imaging of carbon atoms, we studied the imaging of lighter atoms in the presence of heavy ones by using the OAM-CM300FEG/UT to investigate a specimen of $\mathrm{LiCoO}_{2}$, the most commonly used positive electrode materials in lithium rechargeable batteries for portable electronic applications such as laptop computers. The mechanism of energy storage is based on lithium insertion and extraction from the $\mathrm{CoO}_{2}$ host structure, so atomic arrangements of lithium ions have a profound effect on the electrochemical performance. One objective of the study was to attempt to atomically resolve lithium ions in the $\mathrm{LiCoO}_{2}$ specimen.

The $\mathrm{LiCoO}_{2}$ structure consists of $\mathrm{CoO}_{2}$ octahedra with chains of $\mathrm{Li}$ atoms between. The unit cell is hexagonal with $\mathrm{a}=\mathrm{b}=2.816 \AA$ and $\mathrm{c}=14.05 \AA$. In [110] projection the two-dimensional cell is $2.44 \AA$ by $14.05 \AA$ with columns of Li atoms arranged in rows (Fig. 6).

As a first check on the resolution required to observe $\mathrm{Li}$, we computed a series of images from a model of the structure using the weak-phase object approximation (Cowley \& Iijima, 1972) over the resolution range $2 \AA$ to $0.4 \AA$. The series showed that Co atoms would be visible at $2 \AA$ resolution, and that oxygen atoms would appear at $1.4 \AA$ resolution (Fig. 6). The lithium atoms 
would be visible at $1.0 \AA$ resolution, and would become clear at $0.8 \AA$, where all three atom species are clearly distinguished.

Using the Cowley-Moodie multislice theory (Cowley \& Moodie, 1957b), we next computed the phase of the exit-surface wave for resolutions from $0.8 \AA$ to $1.2 \AA$ with increasing specimen thickness from 1 to 40 unit cells thick. For the unit cell repeat of $2.816 \AA$ in the incident beam direction, the series covers $2.8 \AA$ to $113 \AA$. The phase images did not change significantly in the resolution range from $0.8 \AA$ to $1.0 \AA$. The first eighteen of the $0.9 \AA$ images are shown in figure 7 ,

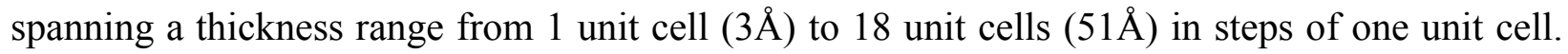
For small thickness (up to 6 unit cells), the heights of the white peaks corresponding to the atom positions are proportional to the scattering power of the atoms weighted by the specimen thickness (the number of atoms in the column under the beam). Oxygen atoms become visible

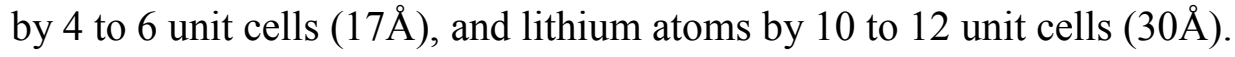

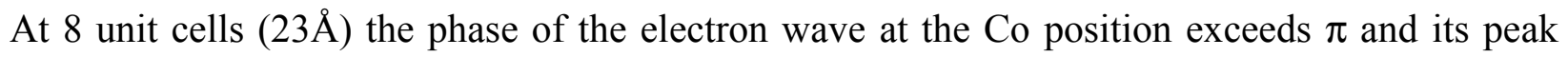
becomes black, leaving the oxygen as the brightest peak. From 12 to 18 unit cells, the oxygen and lithium peaks increase, and the cobalt peak grows from $-\pi$ to become white at 15 unit cells (42A). In the thickness range from 14 to 18 unit cells, oxygen atoms appear as distinct white dots, cobalt atoms are increasingly bright but "fuzzy", and lithium atoms are weak (Fig. 7).

Plots of the ESW phase at the atom positions show the almost linear growth of the peaks with increasing specimen thickness, including the steep growth of the Co peak and the much slower growth of the oxygen and lithium peaks (Fig. 8). The oxygen peak flips phase at 22 unit cells (62A), but the lithium peak remains below $\pi$ up to a thickness of 40 unit cells $(113 \AA)$. The Co 
peak becomes broader (the spot becomes fuzzy) with increasing thickness. The Li also becomes broader, while the oxygen peak appears not to broaden and the oxygen spot remains "sharp".

The OÅM was operated at $300 \mathrm{keV}$ and several focal series of images collected from $\mathrm{LiCoO}_{2}$ samples in [110] orientation. The series were started at nominal defocus values of $-3300 \AA$ and stepped back towards focus in increments of $24 \AA$; each image required 1 second exposure and 5 seconds of CCD readout and defocus change, for a total acquisition time of 2 minutes. The phase image from an ESW reconstruction of 20 images shows all three types of atoms in the sample (Fig. 9a). Comparison with an ESW phase image simulated from the model at 17 unit

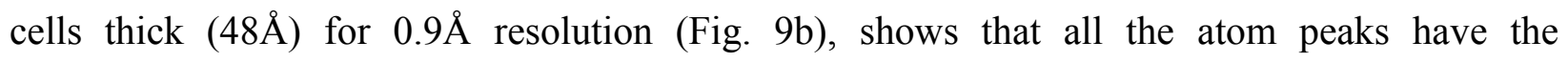
characteristics predicted by the simulations. The O-Co-O units can clearly be distinguished, with each fuzzy Co atom flanked by a pair of bright oxygen atoms (Shao-Horn et al., 2002, 2003). The weak peaks lying between them can be identified as coming from the lithium atoms (arrowed).

An additional check was carried out by running another set of ESW simulations on a model with the Li atoms removed. ESW phase images from this model show no sign of the Li peaks present in the images from the correct structure model. The weak white spots present in the experimental reconstruction appear in the simulation only when the model has the Li atoms present (Fig.10).

\section{DISCUSSION}

It is clear that improved resolution facilitates the imaging of light atoms in compound specimens. At first sight, it appears that $1.54 \AA$ resolution would be sufficient to separate atoms $1.54 \AA$ apart (the distance between the projected positions of the Li atom and the nearest oxygen). However, it turns out that criteria for the observation of light atoms in the presence of heavier atoms are not 
met merely by selecting a resolution equal to the distance between the light atom and its neighbors. The tails produced by the "point-spread" functions generated by the interaction of the electron beam with the surrounding atoms can obscure or even suppress the signal coming from the light atom. In $\mathrm{LiCoO}_{2}$, it requires sampling at $1.0 \AA$ resolution before the $\mathrm{Li}$ atom emerges from the "wakes" generated by its neighbors (figure 6).

The appearance of oxygen atoms in $\mathrm{LiCoO}_{2}$ at $1.4 \AA$ (figure 6) is consistent with previous observations at this resolution (Horiuchi et al., 1991; Wenk et al., 1992; Jia \& Thust, 1999; Jia et al., 2003). Imaging of lighter atoms, such as lithium, requires even better resolution, especially if "atom shape" (peak shape) in the image is to be close to the symmetrical shape of the atom in the specimen. Note that the peaks representing the atoms remain non-circular, due to the influence of surrounding atoms, until extremely high resolutions. Although this effect is most often more noticeable for lighter atoms in the presence of heavy ones, even the Co atoms are distinctly non-circular until resolution is improved from $2 \AA$ to $1.4 \AA$ (figure 6 ). The oxygen atoms are visible at $1.4 \AA$, but do not become round until $0.6 \AA$. The lightest atoms, $\mathrm{Li}$, are most influenced by the presence of other atoms; although they are visible at $1.0 \AA$ resolution, they remain non-circular until $0.4 \AA$. Because the shape effect is caused by the presence of adjoining atoms, it will be strongly specimen dependent.

In our results for $\mathrm{LiCoO}_{2}$, the match between experiment and simulation is not exact. Comparison of the experimental result with the on-axis simulation shows that the specimen was slightly tilted away from the exact zone axis, smearing the oxygen peaks along the diagonal from top right to bottom left and displacing the lithium peaks from their central positions between the O-Co-O units. There may also be some electron beam damage causing atom displacement or specimen buckling (top left and bottom left). 
It is known that specimen tilt reduces dynamical electron scattering, thus making the specimen appear thinner than the simulation (O'Keefe \& Radmilovic, 1993). For this reason, it is likely that the physical thickness of our tilted specimen is somewhat greater than the $48 \AA$ indicated by the matching simulation of the ESW phase.

\section{CONCLUSIONS}

The imaging of lithium completes the range of atoms detectable by HRTEM (except, of course, for $\mathrm{H}$ and $\mathrm{He}$ ). This range now extends from the heavy metals, through non-metals like silicon, oxygen, nitrogen and carbon, to the lightest of all the metals. With the range complete, the HRTEM is confirmed in its position as the preferred instrument for the imaging of atoms. The emergent nanotechnology revolution requires "eyes" - it must be possible to "see" what we have built - and HRTEM at sub-Ångstrom resolution will play an essential role. Our results with the OÅM-CM300FEG/UT foreshadow those to be expected from next-generation TEMs with $\mathrm{C}_{\mathrm{S}^{-}}$ corrected lenses and monochromated electron beams.

\section{ACKNOWLEDGEMENTS}

This report is written as a tribute to Professor J.M. Cowley on the occasion of his 80th birthday. The first author is especially grateful to Professor Cowley for his guidance on the road that has led to the achievement of sub-Ångstrom resolution and the imaging of light atoms. This work was supported by the Director, Office of Science, Office of Basic Energy Sciences, Material Sciences Division, of the U.S. Department of Energy, under contract No. DE-AC03-76SF00098 Additional support was provided by National Science Foundation International Research Fellow Award INT-0000429. Electron microscopy was performed at the CHREM at Arizona State University, and at the NCEM at Lawrence Berkeley National Laboratory. 


\section{REFERENCES}

Allpress, J.G. (1969). The direct observation of structural features and defects in complex oxides by two-dimensional lattice imaging. Mat. Res. Bull. 310, 707-712.

Allpress, J.G., Hewat, E.A., Moodie, A.F. \& SANDers, J.V. (1972). n-beam lattice images, I. Experimental and computed images from $\mathrm{W}_{4} \mathrm{Nb}_{26} \mathrm{O}_{77}$. Acta Cryst. A28, 528-535.

Anstis, G.R., Lynch, D.F., Moodie, A.F. \& O'Keefe, M.A. (1973). n-beam lattice images, III. Upper limits of ionicity in $\mathrm{W}_{4} \mathrm{Nb}_{26} \mathrm{O}_{77}$. Acta Cryst. A29, 138-147.

Anstis, G.R. \& O'KeEFE, M.A. (1976). Resolution-limiting effects in electron microscope images. 34th Ann. Proc. EMSA, Miami Beach, 480-481.

BAKKeR, H., BleEKeR, A. \& MUl, P. (1996). Design and performance of an ultra-high-resolution $300 \mathrm{kV}$ microscope. Ultramicroscopy 64 (1996) 17-34.

Coene, W.M.J., Thust, A., Op De Beeck, M., \& Van Dyck, D. (1996). Maximum-likelihood method for focus-variation image reconstruction in high resolution transmission electron microscopy. Ultramicroscopy 64, 109-135.

Cook, J.M., O'KeEFe, M.A., SMith, D.J. \& StobBs, W.M. (1983). The high resolution electron microscopy of stacking defects in Cu-Zn-Al shape-memory alloy. J. Microscopy 129, 295-306.

Cowley, J. M. \& Moodie, A. F. (1957a). Fourier images. I. The point source. Proc. Phys. Soc. B 70 (1957) 486-496.

Cowley, J. M. \& Moodie, A. F. (1957b). The scattering of electrons by atoms and crystals. I. A new theoretical approach. Acta Cryst. 10, 609-623. 
Cowley, J. M. \& IIJIMA, S. (1972) Electron microscope image contrast for thin crystals. Z. Naturforsch. 27a, 445-451.

DEN DeKKeR, A.J. \& VAN DEN Bos, A. (1997). Resolution: a survey. Journal of the Optical Society of America A 14: (3) 547-557.

Downing, K.H., Meisheng, Hu, Wenk, H.-R \& O'Keefe, M.A. (1990). Resolution of oxygen atoms in staurolite by three-dimensional transmission electron microscopy. Nature 348, 525-528.

Epicier, T., O'Keefe, M.A. \& Thomas, G. (1990). Atomic imaging of 3:2 mullite. Acta Cryst. A46, 948-962.

FRANK, J. (1973). The envelope of electron microscopic transfer functions for partially coherent illumination. Optik 38, 519-536.

Haider, M., Braunshausen, G. \& Schwan, E. (1995). Correction of the spherical aberration of a 200kV TEM by means of a hexapole-corrector. Optik, 99, 167-179.

Horiuchi, S., Matsui, Y., Kitami, Y., Yokoyama, M., Suehara, S., Wu, X. J., Matsui, I. \& KAtsutA, T. (1991). Ultra-high-resolution HVEM (H-1500) newly constructed at NIRIM. II. Application to materials. Ultramicroscopy 39, 231-237.

IJJIMA, S. (1971). High resolution electron microscopy of crystal lattice of titanium-niobium oxide. J. Appl. Phys. 42, 5891-5893.

IIJIMA, S. \& O’KeEFe, M.A. (1979). Determination of defocus values using 'Fourier images' for high resolution electron microscopy. J. Micros. 117, 347-354. 
JiA, C. L. \& Thust, A. (1999). Investigation of atomic displacements at a $\Sigma 3\{111\}$ twin boundary in $\mathrm{BaTiO}_{3}$ by means of phase-retrieval electron microscopy. Phys. Rev. Letts $\mathbf{8 2}$, $5052-5055$.

JiA, C. L., Lentzen, M. \& Urban, K. (2003). Atomic-resolution imaging of oxygen in perovskite ceramics. Science 299, 870-873.

Kisielowski, C., Hetherington, C. J. D., Wang, Y. C., KilaAs, R., O'Keefe, M. A. \& Thust, A. (2001). Imaging columns of the light elements carbon, nitrogen and oxygen at sub-Ångstrom resolution. Ultramicroscopy 89, 243-263.

Lichte, H. (1991). Optimum focus for taking electron holograms. Ultramicroscopy 38, 13-22.

LYNCH, D.F. \&. O'KeEFE, M.A. (1972). n-beam lattice images, II. Methods of calculation. Acta Cryst. A28, 536-548.

Lynch, D. F., Moodie, A. F. \& O'KeEFe, M.A. (1975). n-beam lattice images, V. Use of the charge-density approximation in the interpretation of lattice images. Acta Cryst. A31, 300-307.

MALM, J.-O. \& O'KeEFE, M.A. (1993). Using convergence and spread-of-focus parameters to model spatial and temporal coherence in HRTEM image simulations. 51st Ann Proc. MSA, Cincinnatti, Ohio, 974-975.

O'KeEfe, M.A. (1973). n-beam lattice images, IV. Computed two-dimensional images. Acta Cryst. A29, 389-401. 
O'Keefe, M.A. \& Sanders, J.V. (1975). n-beam lattice images, VI. Degradation of image resolution by a combination of incident-beam divergence and spherical aberration. Acta Cryst. A31, 307-310.

O’KeEfe, M.A., Buseck, P.R. \& IIJIMA, S. (1978). Computed crystal structure images for high resolution electron microscopy. Nature 274, 322-324.

O'KeEfe, M.A. (1979). Resolution-damping functions in non-linear images. 37th Ann. Proc. EMSA, San Antonio, Texas 556-557.

O'KeEFE, M.A. (1993). Using coherent illumination to extend HRTEM resolution: why we need a FEG-TEM for HREM. LBL Symposium on Microstructures of Materials, edited by K. Krishnan (Berkeley: San Francisco Press), pp. 121-126.

O'Keefe, M.A. \& Radmilovic, V. (1993). The effects of small crystal tilts on dynamical scattering: why simulated images are thinner than experimental ones. 51st Ann Proc. MSA, Cincinnatti, Ohio, 980-981.

O'KeEFE, M.A. (1998). Theoretical and practical aspects in computer simulation of high resolution transmission electron microscope images, Proceedings of XIVth Int. Congress for Electron Microscopy 1, 2: 573-574.

O'KeEFE, M.A. (2001). Alpha-null defocus: an optimum defocus condition with relevance for focal-series reconstruction. Microscopy \& Microanalysis 7, 2: 916-917.

O'Keefe, M.A., Nelson, E.C., Wang, Y.C. \& Thust, A. (2001a). Sub-Ångstrom resolution of atomistic structures below 0.8̊̊. Philosophical Magazine B 81, 11: 1861-1878. 
O'Keefe, M.A., Hetherington, C.J.D., Wang, Y.C., Nelson, E.C., Turner, J.H., KisielowSki, C., Malm, J.-O., Mueller, R., Ringnalda, J., Pan, M., \& Thust, A. (2001b). SubÅngstrom high-resolution transmission electron microscopy at 300keV. Ultramicroscopy 89, 4: 215-241.

O'Keefe, M.A., Tiemeijer, P.C. \& Sidorov, M.V. (2002). Estimation of the electron beam energy spread for TEM information limit. Microscopy \& Microanalysis 8, 2: 480-481.

RAYLEIGH, LORD (a.k.a. StRUTT, J. W.). (1874). On the manufacture and theory of diffraction gratings. Philosophical Magazine 47, 310: 81-93.

SCHERZER, O. (1949). The theoretical resolution limit of the electron microscope. J. Applied Physics, 20, 20-29.

Schiske, P. (1973) in Image Processing And Computer-Aided Design, Ed. P.W. Hawkes, Acad. Press, London, pp.82-90.

Shao-Horn, Y., O’Keefe, M.A., Nelson, E.C., Croguennec, L. \& Delmas, C. (2002). Atomic resolution of lithium ions in $\mathrm{LiCoO}_{2}$. Fall Meeting of the Materials Research Society, Symposium $G$, Boston, Massachusetts.

Shao-Horn, Y., Croguennec, L. \& Delmas, C., Nelson, E.C., O’Keefe, M.A. (2003). Atomic resolution of lithium ions in $\mathrm{LiCoO}_{2}$. Nature Materials 2, 464-467; advance on-line publication 15 June 2003 (doi: 10.1038/nmat922).

Thust, A., Coene, W.M.J., Op De Beeck, M., \& Van Dyck, D. (1996). Focal-series reconstruction in HRTEM: simulation studies on non-periodic objects. Ultramicroscopy, 64, 211-230. 
TYPKE, D. \& DiERKSEN, K. (1995). Determination of image aberrations in high-resolution electron microscopy using diffractogram and cross-correlation methods. Optik 99, 4: 155-166.

VAN DyCK, D. \& OP DE BEECK, M. (1990). New direct methods for phase and structure retrieval in HREM. Proceedings of the 12th International Congress for Electron Microscopy, edited by L.D. Peachy and D.B. Williams (Seattle, Washington), pp. 26-27.

WADE, R.H. \& FRANK, J. (1977). Electron microscope transfer functions for partially coherent axial illumination and chromatic defocus spread. Optik 49, 81-92.

Wang, Y.C., Fitzgerald, A., Nelson, E.C., Song, C., O’Keefe, M.A. \& Kisielowski, C. (1999). Effect of correction of the 3-fold astigmatism on HREM lattice imaging with information below 100 pm. Microscopy \& Microanalysis 6, 2: 822-823.

Wenk, H.-R., Downing, K.H., Meisheng, Hu \& O'Keefe, M.A. (1992). 3d structure determination from electron-microscope images: electron crystallography of staurolite. Acta Cryst. A48, 700-716. 


\section{FIGURE CAPTIONS}

Figure 1. Pair of images of $\mathrm{Ti}_{2} \mathrm{Nb}_{10} \mathrm{O}_{29}$ obtained on a JEOL 100B TEM shows smaller spacings at larger underfocus. a: Large $3 \times 2$ tunnels within the $4 \times 3$ blocks of metal-oxygen octahedra are visible as white dots at Scherzer defocus. b: At twice the underfocus, small tunnels between the $4 \times 3$ blocks of metal-oxygen octahedra are visible, but large tunnels are no longer seen. Reprinted from Nature 274, M.A. O’Keefe, P.R. Buseck and S. Iijima, “Computed crystal structure images for high resolution electron microscopy", pp322-324, copyright (1978), with permission from Nature.

Figure 2. Focal series reconstruction improves resolution and images oxygen atoms. a: Model of staurolite in [001] projection; small spheres represent oxygen, large Al and Si. b: Averaged image from ARM-1000 (1.6̊̊ resolution) at Scherzer defocus shows metal atoms. c: Image reconstructed from a focal series of five images shows oxygen atoms as well. d: Simulation at $1.4 \AA$ resolution. Arrows point to resolved oxygen atoms. Reprinted from Acta Cryst. A48, H.R. Wenk, K.H. Downing, Hu Meisheng and M.A. O'Keefe, “3d structure determination from electron-microscope images: electron crystallography of staurolite", pp700-716, copyright (1992), with permission from IUCr.

Figure 3. Contrast transfer functions out to $1.5 \AA^{-1}$ for $300 \mathrm{keV}$ electron beam energy and $0.6 \mathrm{~mm}$ spherical aberration. a: Standard CM300FEG/UT had $36 \AA$ spread of focus and $1.07 \AA$ information limit. b: OAM-CM300 has $20 \AA$ spread of focus and $0.78 \AA$ information limit. c: Spatial coherence (0.25 milliradian) limits OAM transfer at Scherzer defocus. d: At second cross-over defocus $(n=2)$, transfer moves to higher frequencies and mid-range frequencies are inverted. e: For $n=36$, transfer extends to below $1 \AA$. 
Figure 4. Focus-variation transfer functions at $300 \mathrm{keV}$ and $\mathrm{C}_{\mathrm{S}}$ of $0.6 \mathrm{~mm}$ for four sets of diffracted beams from [110] diamond. Packet limits (marked) create an overlap range in which all beams can contribute to a single image out to $0.89 \AA$ resolution. Reprinted from Ultramicroscopy 89, M.A. O’Keefe, C.J.D. Hetherington, Y.C. Wang, E.C. Nelson, J.H. Turner, C. Kisielowski, J.-O. Malm, R. Mueller, J. Ringnalda, M. Pan and A. Thust, "Sub-Ångstrom High-Resolution Transmission Electron Microscopy at 300keV",.p234, copyright (2001), with permission from Elsevier.

Figure 5. OÅM-CM300 images of diamond in [110] orientation. a: Before correction of 3-fold astigmatism. b: Diffractogram has weak 004 spot. c: Averaged image. d: Simulation with 2.25 $\mu \mathrm{m}$ 3-fold astigmatism. e: Mirrored horizontally. f: Mirrored vertically. g: Line trace shows $0.89 \AA$ spacing. h: After correction of 3-fold astigmatism. i: Diffractogram has strong 004 spot. j: Phase of exit-surface-wave reconstruction from a focal series of 20 images. Reprinted from Ultramicroscopy 89, M.A. O'Keefe, C.J.D. Hetherington, Y.C. Wang, E.C. Nelson, J.H. Turner, C. Kisielowski, J.-O. Malm, R. Mueller, J. Ringnalda, M. Pan and A. Thust, "Sub-Ångstrom High-Resolution Transmission Electron Microscopy at 300keV",.pp234-238, copyright (2001), with permission from Elsevier.

Figure 6. $\mathrm{LiCoO}_{2}$ model (left and right) projected in [110] direction shows horizontal rows of $\mathrm{Li}, \mathrm{Co}$ and $\mathrm{O}$ atoms within cell of size $2.44 \AA$ by $14.05 \AA$. Weak-phase-object image series (black atoms) simulated in [110] orientation for increasing resolution (marked) shows atoms: Co at $2 \AA$, $\mathrm{O}$ at $1.4 \AA$, and Li at $1 \AA$. Each image shows 2 by 1 unit cells.

Figure 7. $\mathrm{LiCoO}_{2}$ model and ESW-phase images in [110] orientation. Images simulated at $0.9 \AA$ resolution for increasing specimen thickness (marked in unit cells of $2.816 \AA$ ). Arrows point to horizontal rows of $\mathrm{Co}, \mathrm{O}$, and $\mathrm{Li}$ atom columns. Each image shows 1 unit cell. 
Figure 8. Profiles across phase of simulated $\mathrm{LiCoO}_{2} \mathrm{ESW}$ images show phase increases at atom positions for increasing specimen thickness. Slope of phase increase is higher for heavier atoms.

Figure 9. a: $\mathrm{LiCoO}_{2} \mathrm{ESW}$-phase image, reconstructed from 20 experimental images, shows rows of $\mathrm{Li}$ atoms between $\mathrm{O}-\mathrm{Co}-\mathrm{O}$ groups. b: Inset ESW-phase simulation for $48 \AA$ thickness. Reprinted from Nature Materials 2, Yang Shao-Horn, Laurence Croguennec, Claude Delmas, E. Chris Nelson \& Michael A. O'Keefe, “Atomic resolution of lithium ions in $\mathrm{LiCoO}_{2}$ ”, pp464-467, advance on-line publication 15 June 2003 (doi: 10.1038/nmat922), copyright (2003), with permission from Nature.

Figure 10. $\mathrm{LiCoO}_{2}$ models and ESW-phase images in [110] orientation for $\mathrm{LiCoO}_{2}$ without lithium atoms (upper) and with lithium atoms (lower). Images are simulated at $0.9 \AA$ resolution

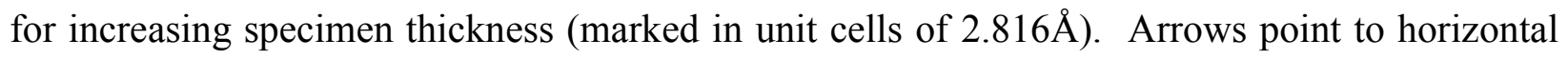
row of Li atom columns. Each image shows 1 unit cell. 


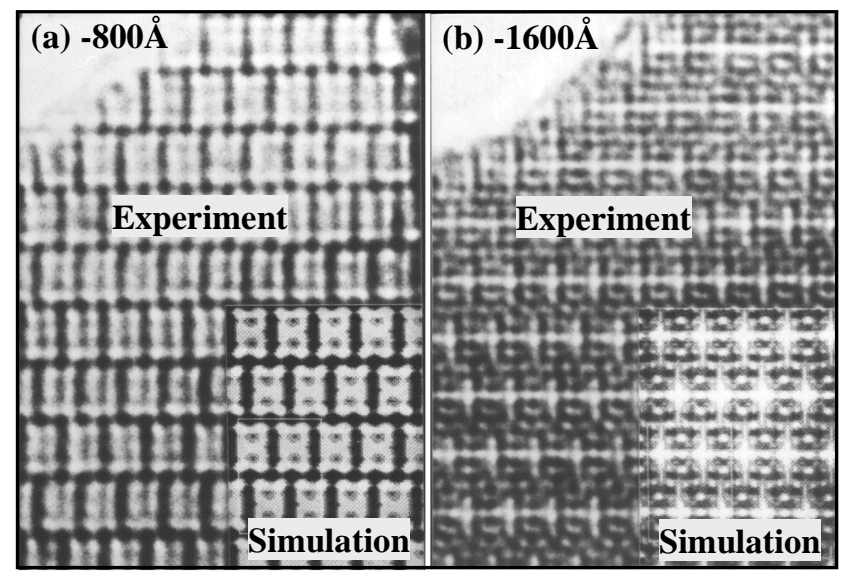

Figure 1. Pair of images of $\mathrm{Ti}_{2} \mathrm{Nb}_{10} \mathrm{O}_{29}$ obtained on a JEOL 100B TEM. a: Large $3 \times 2$ tunnels within the $4 \times 3$ blocks of metal-oxygen octahedra are visible as white dots at Scherzer defocus. b: At twice the underfocus small tunnels between the $4 \times 3$ blocks of metal-oxygen octahedra are visible, but large tunnels are not (O'Keefe et al., 1978). 


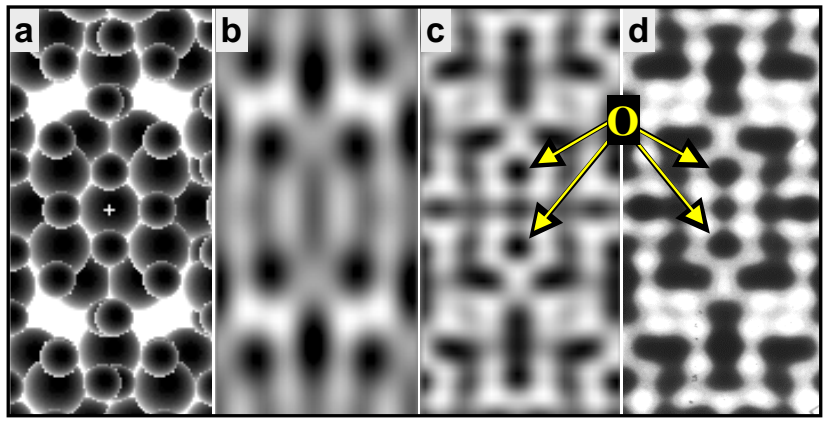

Figure 2. a: Model of staurolite in [001] projection; small spheres represent oxygen, large are Al and Si. b: Averaged image from ARM-1000 (1.6̊ resolution) at Scherzer defocus. c: Image reconstructed from a focal series of five images. d: Simulation at $1.4 \AA$ resolution. Arrows point to resolved oxygen atoms (Wenk et al., 1992) 


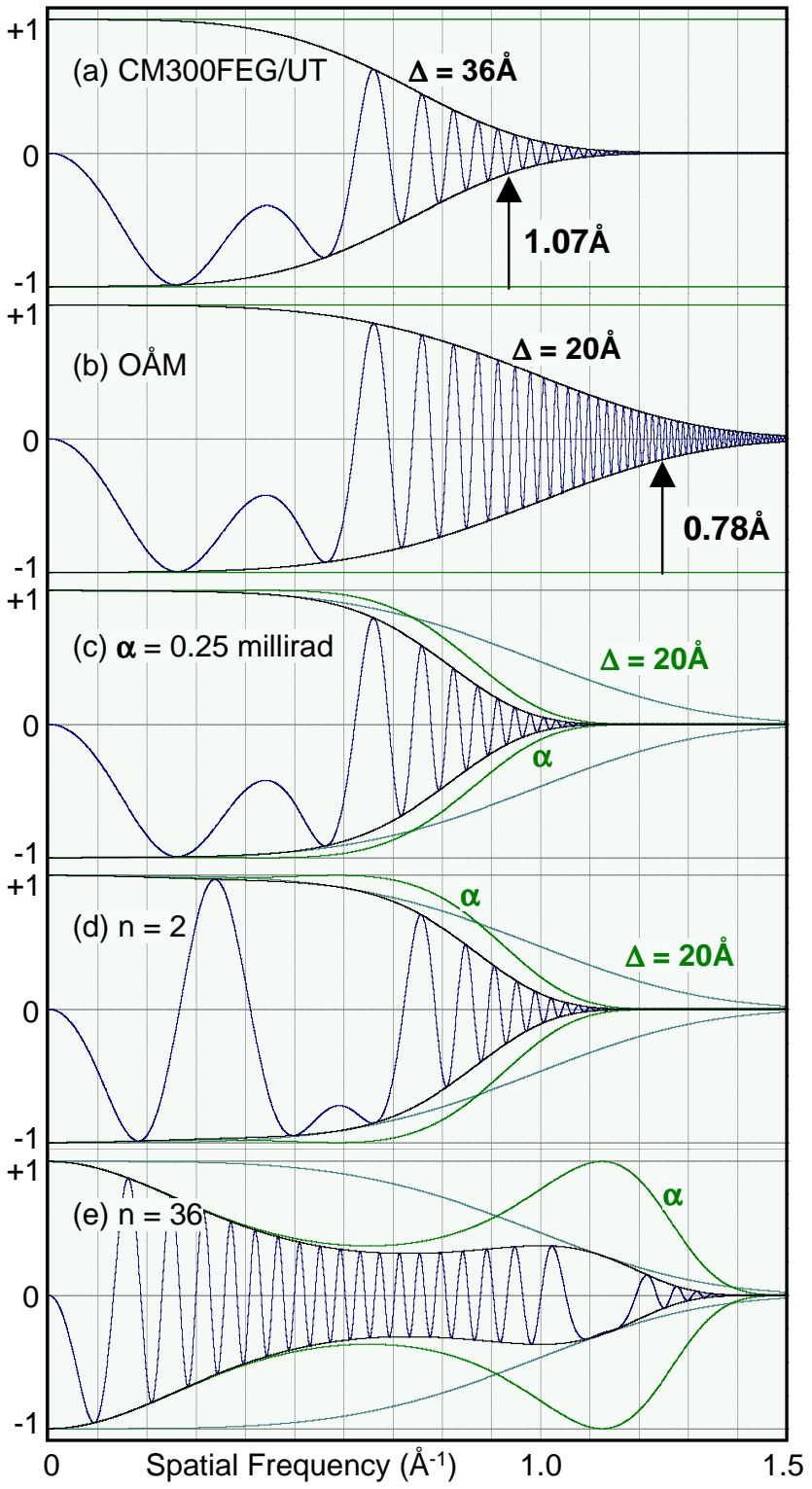

Figure 3. Contrast transfer functions out to $1.5 \AA^{-1}$ for $300 \mathrm{keV}$ electron beam energy and $0.6 \mathrm{~mm}$ spherical aberration. a: Standard CM300FEG/UT has $36 \AA$ spread of focus and $1.07 \AA$ information limit. b: OAM-CM300 has $20 \AA$ spread of focus and $0.78 \AA ̊$ information limit. c: Spatial coherence ( 0.25 milliradian) limits OÅM transfer at Scherzer defocus. d: At second cross-over defocus $(n=2)$, transfer moves to higher frequencies and mid-range frequencies are inverted. e: For $\mathrm{n}=36$, transfer is below $1 \AA$. 


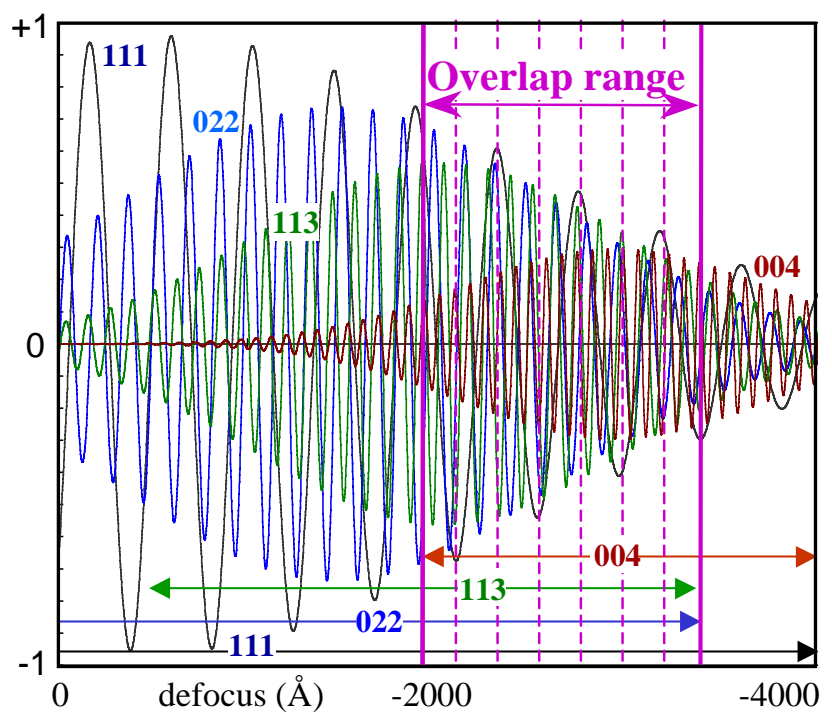

Figure 4. Focus-variation transfer functions at $300 \mathrm{keV}$ and $0.6 \mathrm{~mm} \mathrm{C}_{\mathrm{S}}$ for four sets of diffracted beams from [110] diamond. Packet limits (arrows) create an overlap range (marked) in which all beams can contribute to a single image out to $0.89 \AA ̊$ resolution (O'Keefe et al., 2001a,b). 


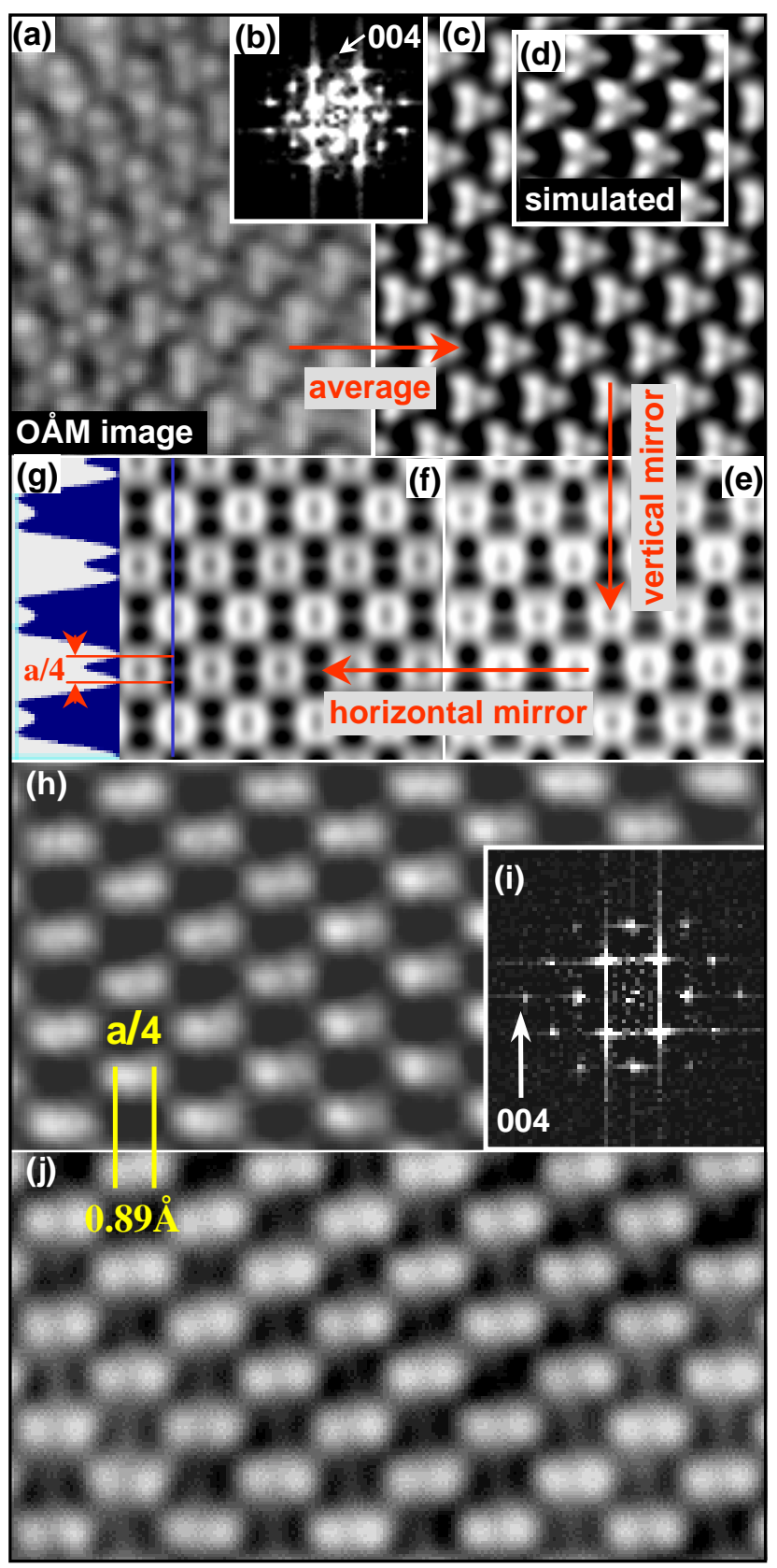

Figure 5. OÅM-CM300 images of diamond in [110] orientation. a: Before correction of 3-fold astigmatism. b: Diffractogram has weak 004 spot. c: Averaged image. d: Simulation with $2.25 \mu \mathrm{m} 3$-fold astigmatism. e: Mirrored horizontally. f: Mirrored vertically. $\mathbf{g}$ : Line trace shows $0.89 \AA$ spacing. h: After correction of 3-fold astigmatism. i: Diffractogram has strong 004 spot. j: Phase of exit-surface-wave reconstruction from a focal series (O'Keefe et al., 2001a,b). 


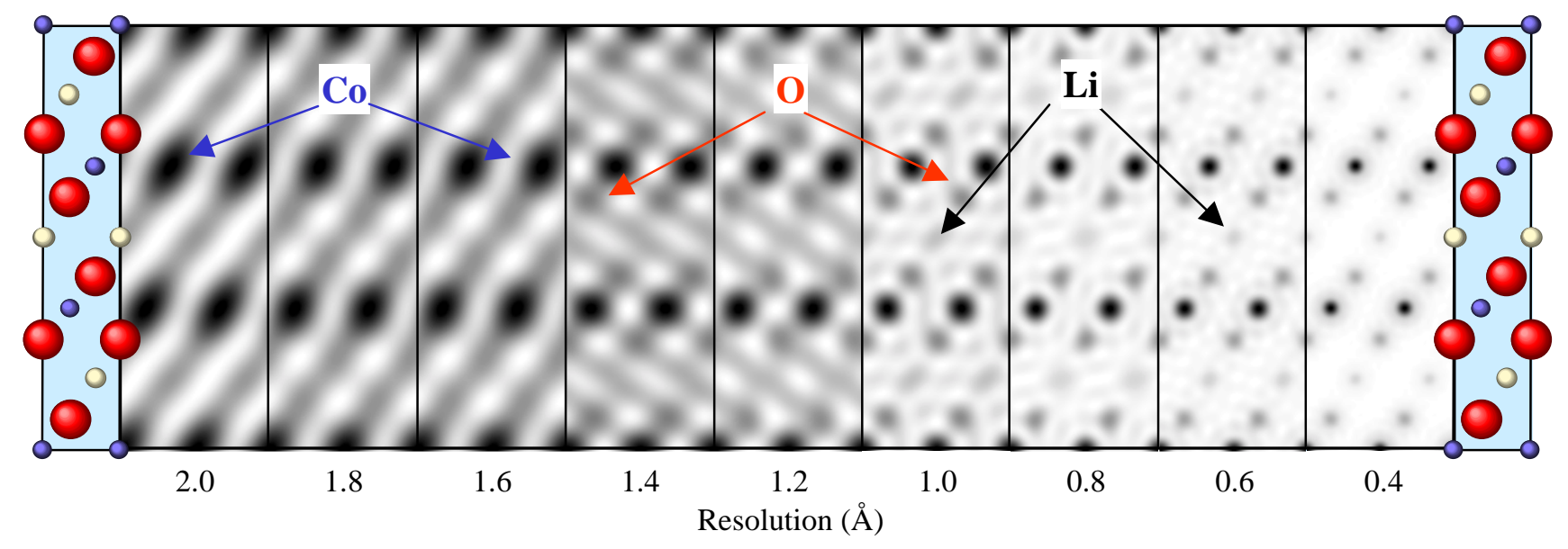

Figure 6. $\mathrm{LiCoO}_{2}$ model (left and right) projected in [110] direction shows horizontal rows of Li, Co and $\mathrm{O}$ atoms within cell of size $2.44 \AA$ by $14.05 \AA$. Weak-phase-object image series (black atoms) simulated in [110] orientation for increasing resolution (marked) shows atoms: Co at $2 \AA, \mathrm{O}$ at $1.4 \AA$, and Li at $1 \AA$. Each image shows 2 by 1 unit cells. 


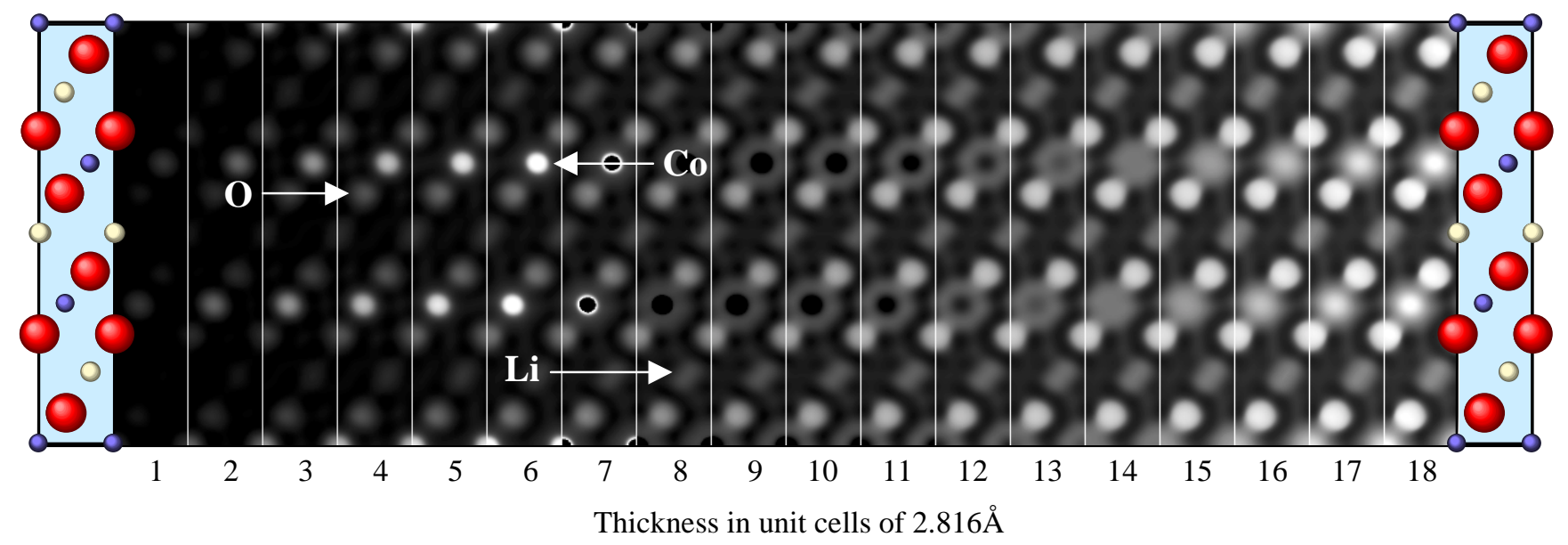

Figure 7. $\mathrm{LiCoO}_{2}$ model and ESW-phase images in [110] orientation. Images simulated at $0.9 \AA$ resolution for increasing specimen thickness (marked in unit cells of 2.816 $\mathrm{\AA}$ ). Arrows point to horizontal rows of Co, O, and Li atom columns. Each image shows 1 unit cell. 

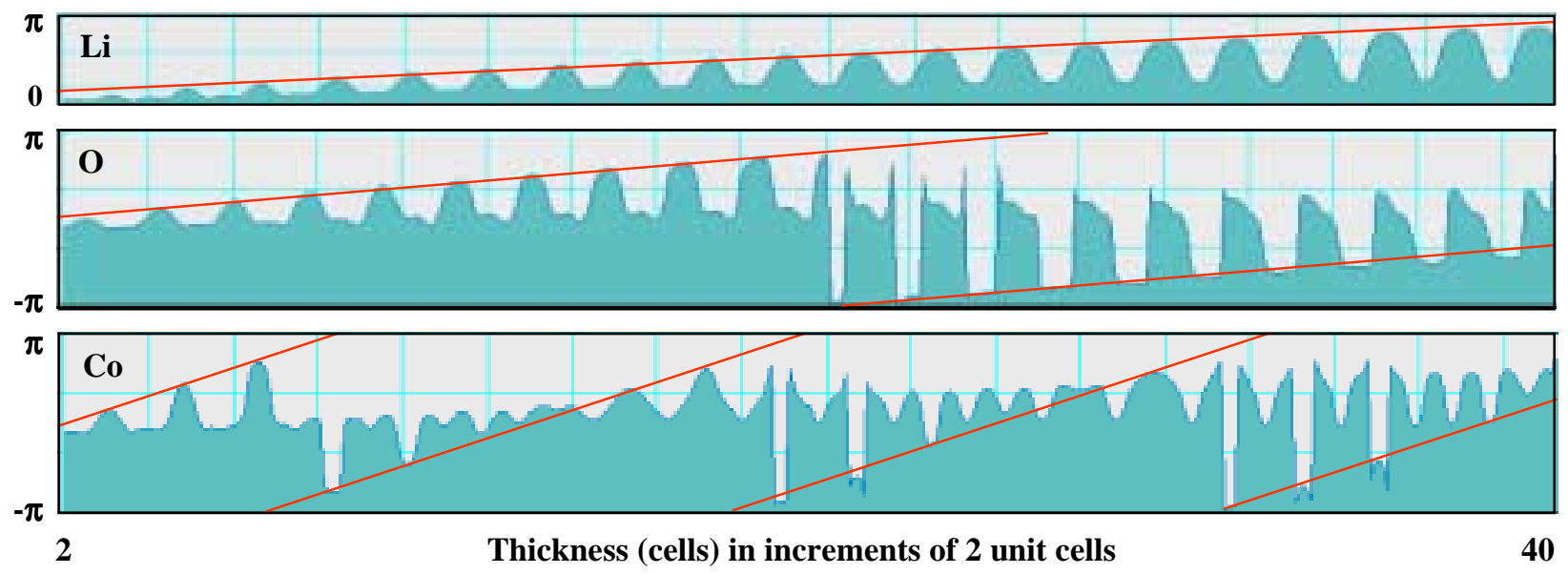

Figure 8. Profiles across phase of simulated $\mathrm{LiCoO}_{2} \mathrm{ESW}$ images show phase increases at atom positions for increasing specimen thickness. Slope of phase increase is higher for heavier atoms. 


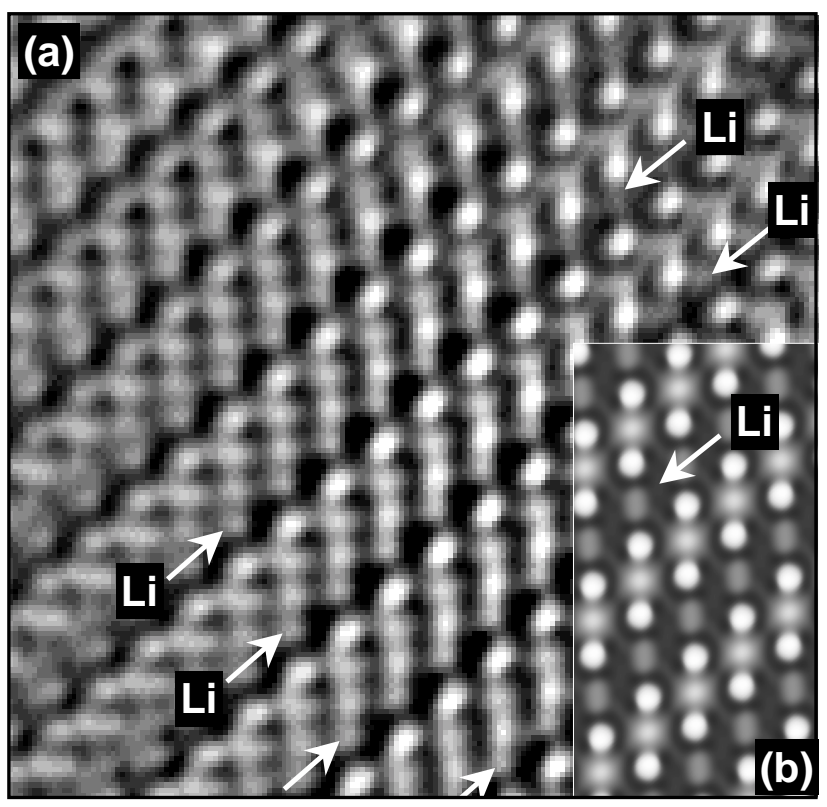

Figure 9. a: $\mathrm{LiCoO}_{2} \mathrm{ESW}$-phase image, reconstructed from 20 experimental images, shows rows of Li atoms between O-Co-O groups. b: Inset ESW-phase simulation for $48 \AA$ thickness. 


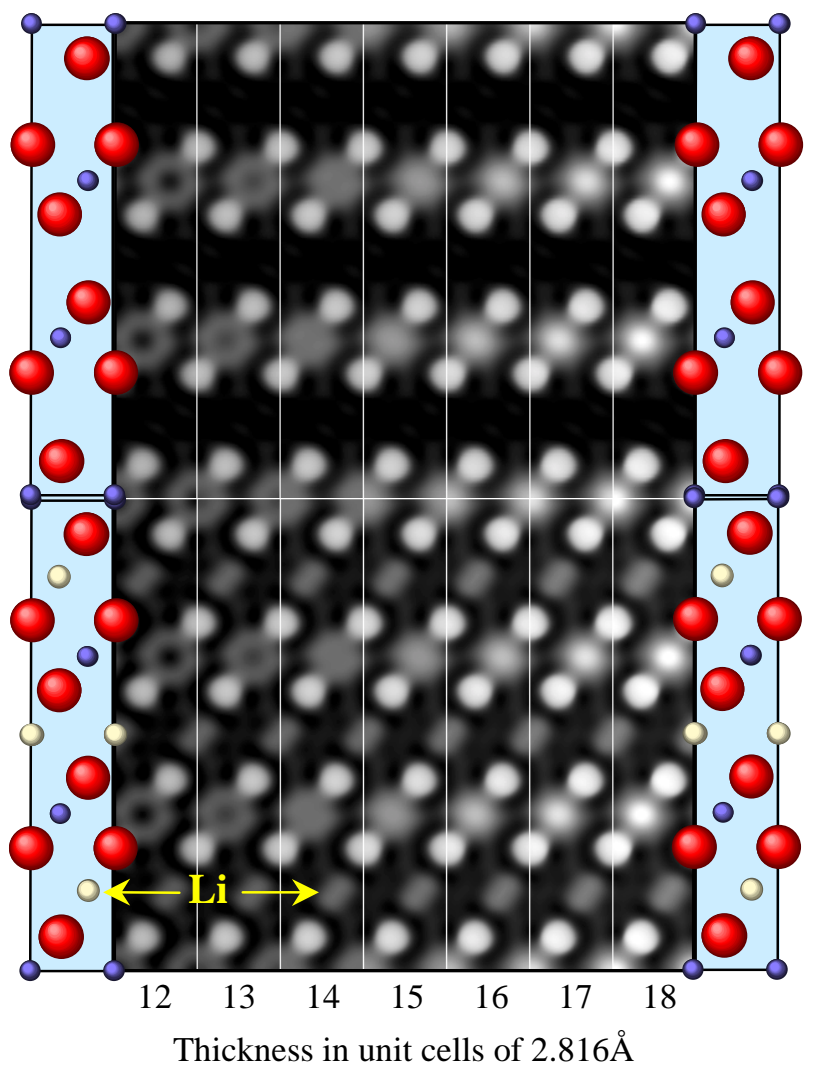

Figure 10. $\mathrm{LiCoO}_{2}$ models and $\mathrm{ESW}$-phase images in [110] orientation for $\mathrm{LiCoO}_{2}$ without lithium atoms (upper) and with lithium atoms (lower). Images are simulated at $0.9 \AA$ resolution for increasing specimen thickness (marked in unit cells of $2.816 \AA$ ). Arrows point to horizontal row of Li atom columns. Each image shows 1 unit cell. 